\title{
The Investigation on the Mechanical Endurance Degradation of Nafion Membrane
}

\author{
Y. Xiao, C. Cho* \\ Department of Mechanical Engineering \\ Inha University \\ Incheon, South Korea
}

\begin{abstract}
As a solution of high efficiency and clean energy, fuel cell technologies, especially proton exchange membrane fuel cell (PEMFC), have caught extensive attention. However, after decades of development, the performances of PEMFCs are far from achieving the target from the Department of Energy (DOE). So, further understanding of the degradation mechanism is needed to overcome this obstacle. Due to the importance of proton exchange membrane in a PEMFC, the degradation of the membrane, such as hygrothermal aging effect on its properties, are particularly necessary. In this work, a thick membrane (Nafion N117) which is always used as an ionic polymer for the PEMFCs has been analyzed. Experimental investigation is performed for understanding the mechanical endurance of the bare membranes under different loading conditions. Tensile tests are conducted to compare the mechanical property evolution. Taking the test data as a desired mechanical response, . a model with both viscoelasticity and plasticity involved in was built and investigated by mechanics-based simulations which are performed using the finite element method (ABAQUS). By optimizing the parameters of viscoelastic-plastic model, the best agreement to the desired mechanical behaviour was achieved. And the parameters will be compared and analyzed to find out the variation of the polymer's structure during the degradation process.
\end{abstract}

Keywords-PEMFC, nafion; fracture test; hygrothermal aging; mechanical endurance

\section{INTRODUCTION}

PEM fuel cell has very high performance in a wide working range with good dynamic characteristics and it works at low temperature. PEM fuel cell also has showed high efficiency of electrical conversion and the total efficiency can be even higher by making full use of the heat generated during the operation. It generates electricity without any emissions and most of the materials employed can be reused or recycled [1]. It was reported in 2010 that PEM fuel cell can reach $\sim 60 \%$ electricity conversion efficiency and $80 \%$ energy cogeneration (electrical and thermal ) efficiency with more than $90 \%$ reduction of carbon and pollution emissions .

But before that, the low durability of PEM fuel cell is the primary problems that need to be solved. The DOE (department of energy) target for the life time of fuel cell is more than 5000 hours for transportation applications by 2015 and 40000 hours for stationary applications by 2011 . According to this target, now the performance of PEM fuel cell is far from achieving the target [2]. So further understanding of the degradation mechanism and development of durability analysis methods are needed to overcome this obstacle.

To deal with the durability analysis of PEMFC, it is necessary to carry out a further understanding of each component response, especially the electrolyte membrane. Among the perfluorosulfonic acid (PFSA) polymers, the sulfonated tetrafluoroethylene copolymer developed and manufactured by DuPontTM, with the commercial name Nafion, has been the most widely utilized.

However, the mechanical degradation of Nafion after numbers of operation cycles was seldom mentioned in previous research. According to the experimental investigations, the failures occurred not only after long time continuous operating but also manifold cyclic operations. Therefore, the variation of Nafion structure after a certain number of operating cycles should be investigated and analyzed. Nonetheless, the experimental to investigate the variation is difficult to conduct directly. To overcome the experimental limitations, we suggest using numerical method here.

In this paper, inverse design problem technique is used to abstracting the viscoelastic and plastic properties from the simple tensile test results obtained from different specimens (untreated, temperature aged and humidity aged ones). Besides the properties abstracted which can be used as the input for the built-in material model in ABAQUS, the result of this paper also inferred the variation of the Nafion network.

\section{EXPERIMENTAL AND PROCEDURES}

\section{A. Materials}

Non-reinforced films based on chemically stabilized Perfluorosulfonate acid (PFSA) and Polytetrafluoro-ethylene (PTFE) copolymer in the acid $\left(\mathrm{H}^{+}\right)$form, which was obtained from Dupont Company with the commercial name Nafion ${ }^{\circledR}$ N117.

\section{B. Specimen}

The specimens for the tensile tests are designed according to ASTM standard D638 [3]. The dimensions of a dog-bone specimen are shown in Fig. 1 . 


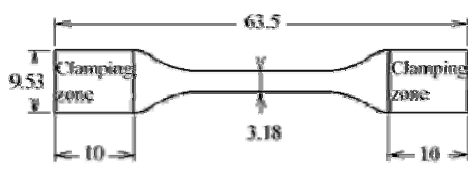

Unit: mint

FIGURE I. THE DIMENSIONS OF A DOG-BONE SPECIMEN

\section{Treatment}

Within an operating circle of the PEM fuel cell, the chemical energy of the fuel is converted into electrical energy through an electrochemical reaction. The diffusion of reactants, the oxidation and reduction of reactants and the conduction of protons, they all take place in the membrane electrode assembly (MEA) where the temperature, humidity and external compressive load have very high variation. The MEA bears the temperature as high as $95^{\circ} \mathrm{C}$ and the humidity from $\mathrm{RH} 30 \%$ to $\mathrm{RH} 90 \%$ [4]. So the humidity and temperature cycling is set as shown in Fig. 2.

All the specimens are divided into three groups, untreated, humidity cycling aged, and temperature cycling aged. Both humidity and temperature aged specimens were maintained in the temperature \& humidity incubator for 12 cycles using THME from JEIO TECH equipment. To avoid the influence of temperature and humidity residual, all the specimens, untreated and aged for 12 cycles, were maintained in room conditions $\left(25^{\circ} \mathrm{C}\right.$ and $\left.\mathrm{RH} 30 \%\right)$ for 24 hours before testing.

All the samples, including untreated, humidity cycling aged and temperature cycling aged ones, are tested at ambient conditions $\left(20^{\circ} \mathrm{C}, \mathrm{RH} 30 \%\right)$ at the strain rate of 0.001 .

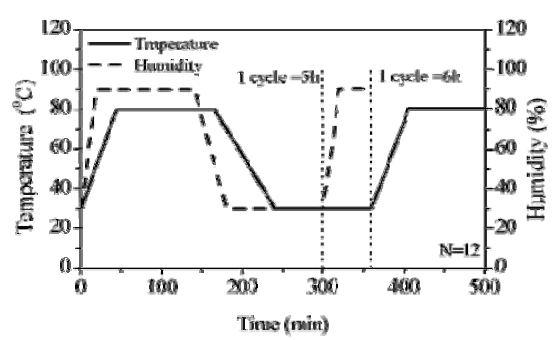

FIGURE II. THE CURVES OF HUMIDITY AND TEMPERATURE CYCLING WITH ONE PERIOD.

\section{Results and Discussion}

As we know, the response of Nafion membrane includes both intermolecular resistance and network stress [5]. Moreover, the total response can be divided into two zones termed as pre-yield and post-yield zones by the potential barrier. After the post yielding, the total response is nearly linear, so we cropped the curves with the true strain range from 0 to 0.18 in order to have a clearer scope of yielding behavior. The curves of true stress-true strain of Nafion N117 dog-bone specimens are shown in Fig. 3 (b).
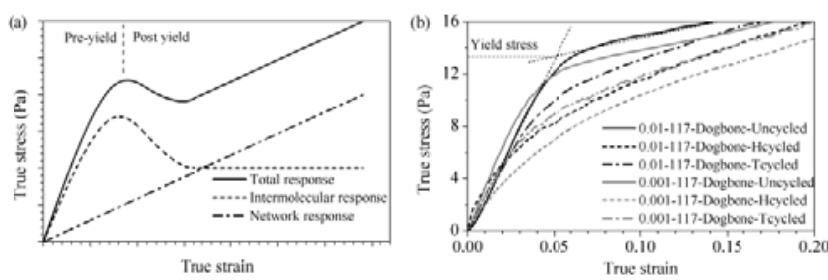

FIGURE III. (A) TRUE STRESS- TRUE STRAIN CURVE OF A TYPICAL POLYMER AND DIFFERENT ZONES. (B) THE TRUE STRESS-TRUE STRAIN CURVES OF N117 DOG-BONE TENSILE TEST UNDER DIFFERENT STRAIN RATES (0.01 AND 0.001) AND DIFFERENT CYCLING TREATMENTS

The stress at the intersection of linear fits to the pre-yield zone slope and the immediate post-yield zone slope is named the yield stress. The yield stress usually referred that can be affected by both deformation rate and temperature. In Fig. 3(b) we can tell it is also affected by aging treatment.

The tensile response of Nafion N117 in terms of true stress and true strain for both treated and untreated samples under strain rate 0.001 at a larger strain is shown in Fig.4.

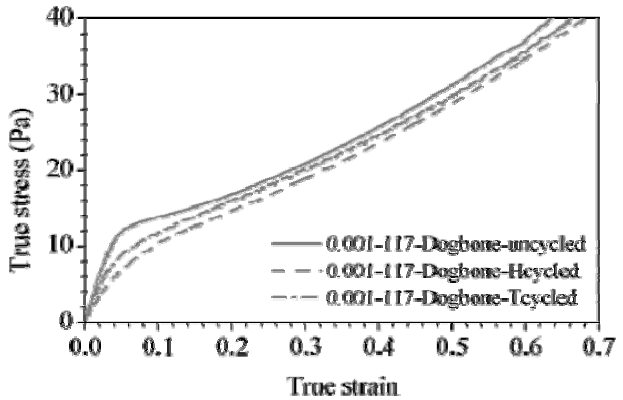

FIGURE IV. THE LOADING BEHAVIOR OF UNTREATED NAFION N117 SAMPLES AT THE STRAIN RATE OF 0.001 .

As we know, the mechanical response of Nafion is very complicated. Boyce and Silberstein presented an ElasticViscoplastic Constitutive Model whose framework follows the previous models [6] with thermo dependence, time dependence and swelling effect $[5,7,8]$ in their prior work. This model consists of an intermolecular deformation mechanism and a molecular network alignment mechanism.

\section{MOdEL FITTING}

\section{A. Two-Layer Viscoplastic Model for Nafion}

The model used in this work is the two-layer viscoplastic model [9] which is available in the ABAQUS package. Based on the observed behavior, choosing this model provides a possibility that apply temperature and hydration gradients as two separate field variables to study mechanical stresses developed in the membrane. A one-dimensional rheological representation of this model is shown in Fig 5.

\section{B. Parameter Fitting}

Viscous behaviour of the material is assumed to be governed by the Norton-Hoff rate law. And a time-hardening power law for the viscous behaviour has been chosen and $\mathrm{m}$ has been set equal to zero. Following the procedure published 
by Roham Solasi et al [10], the optimized parameters are given in Table 1 and Table 2.

TABLE I. TWO-LAYER VISCOPLASTICITY PARAMETERS.

\begin{tabular}{l|lll}
\hline & $\mathbf{A}\left(\mathbf{N}^{-\mathbf{n}} \mathbf{m}^{2 \mathbf{n}} / \mathbf{s}\right)$ & $\mathbf{n}$ & $\mathbf{f}$ \\
\hline Untreated & $5.92 \mathrm{e}-8$ & 6.91 & 0.673 \\
T-cycled & $1.87 \mathrm{e}-6$ & 6.91 & 0.673 \\
H-cycled & $5.92 \mathrm{e}-5$ & 6.91 & 0.673 \\
\hline
\end{tabular}

TABLE II. ELASTIC-PLASTIC PARAMETERS

\begin{tabular}{l|lllll}
\hline & Elastic & \multicolumn{3}{l}{ Plastic } \\
\cline { 2 - 3 } \cline { 5 - 6 } & $\mathrm{E}_{\mathrm{e}}(\mathrm{Mpa})$ & $v$ & & $\begin{array}{c}\sigma_{1}(\mathrm{Mpa}) \\
\left(\varepsilon_{\mathrm{p}}=0\right.\end{array}$ & $\begin{array}{l}\sigma_{2}(\mathrm{Mpa}) \\
\end{array}$ \\
& 300 & 0.4 & 5 & $6 \varepsilon_{\mathrm{p}}=0.6$ \\
\hline Untreated & 300 & 0.4 & 5 & 60 \\
T-cycled & 300 & 0.4 & 5 & 60 \\
H-cycled & 300 & & & 60 \\
\hline
\end{tabular}

\section{Results and Discussion}

True stress-true strain simulation results for three different treatments (untreated, T-cycled and H-cycled) are compared with the experiment results in Fig 6.

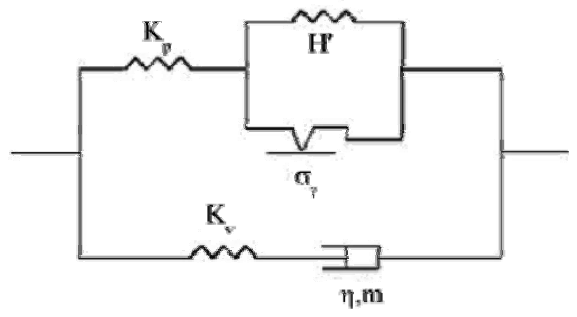

FIGURE V. ONE-DIMENSIONAL RHEOLOGICAL REPRESENTATION OF THE TWO-LAYER VISCO-PLASTICITY MODEL.

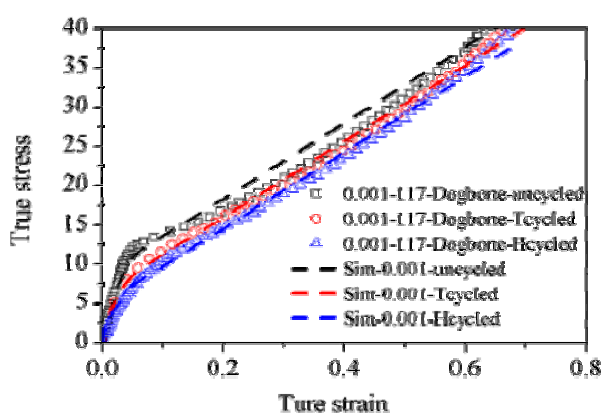

FIGURE VI. COMPARISON BETWEEN SIMULATED CURVES ANS EXPERIMENTAL DATA.

The simulated curves show a very good agreement to the experiment data. The coefficient of determination of each pair of curves is over 0.98 (for untreated specimen $R^{2}=0.988$, for
T-cycled specimen $\mathrm{R}^{2}=0.996$, for $\mathrm{H}$-cycled specimen $\mathrm{R}^{2}=0.997$ ).

The tensile response of Nafion N117 in terms of true stress and true strain for both treated and untreated samples under multiple strain rates is shown in Fig. 3. It can be obviously observed that both the thermal and hygroscopic treatment lead to a decrease in the strength of Nafion N117, in terms of elastic modulus and yielding stress. When the specimens were stretched at a lower strain rate, the impact was greater.

But the parameters obtained by curve fitting showed a different result. As shown in Table 1 and Table 2, the parameters for different treatments are the same except the parameter A, power law multiplier. That is to say, only the creep portion of Nafion was influenced by the thermal and hygroscopic treatment. It is a very interesting finding which can infer the further research directions of degradation associated Nafion micro-structure variation.

\section{CONCLUSION}

From the discussion above, we can get the following conclusions:

(1) Both the thermal and hygroscopic treatments lead to a decrease in the strength of Nafion N117;

(2) Curve fitting shows that only the power law multiplier of the model is affected by the cyclic treatments.

(3)The multiplier increased two orders of magnitude after 12 cycles of thermal treatment and it increased three orders of magnitude after hygroscopic treatment with the same cycles.

\section{ACKNOWLEDGEMENTS}

This work was supported by Inha University.

\section{REFERENCES}

[1] F. Barbir and T. Gomez, Efficiency and economics of proton exchange membrane (PEM) fuel cells, International Journal of Hydrogen Energy, 21, pp. 891-901, 1996.

[2] Y. Wang, K. S. Chen, J. Mishler, S. C. Cho, and X. C. Adroher, A review of polymer electrolyte membrane fuel cells: Technology, applications, and needs on fundamental research, Applied Energy, 88, pp. 981-1007, 2011.

[3] ASTM, " D638-10 Tensile properties of plastics," vol. D638, 2010.

[4] M. F. Peker, O. N. Cora, and M. Koc, Investigations on the variation of corrosion and contact resistance characteristics of metallic bipolar plates manufactured under long-run conditions, International Journal of Hydrogen Energy, 36, pp. 15427-15436, 2011.

[5] E. M. Arruda, M. C. Boyce, and R. Jayachandran, Effects of Strain-Rate, Temperature and Thermomechanical Coupling on the Finite Strain Deformation of Glassy-Polymers, Mechanics of Materials, 19, pp. 193212, 1995.

[6] M. N. Silberstein and M. C. Boyce, Constitutive modeling of the rate, temperature, and hydration dependent deformation response of Nafion to monotonic and cyclic loading, Journal of Power Sources, 195, pp. 5692-5706, 2010.

[7] A. D. Mulliken and M. C. Boyce, Mechanics of the rate-dependent elastic-plastic deformation of glassy polymers from low to high strain rates, International Journal of Solids and Structures, 43, pp. 1331-1356, 2006.

[8] J. S. Bergstrom and M. C. Boyce, Constitutive modeling of the large strain time-dependent behavior of elastomers, Journal of the Mechanics and Physics of Solids, 46, pp. 931-954, 1998. 
[9] ABAQUS Analysis User's Manual, V6.11, 2011.

[10] R. Solasi, Y. Zou, X. Huang, and K. Reifsnider, A time and hydration dependent viscoplastic model for polyelectrolyte membranes in fuel cells, Mechanics of Time-Dependent Materials, 12, pp. 15-30, 2007 